\title{
The Silent Injustices against Men in Maximum Security Prison and the Need for Forgiveness Therapy: Two Case Studies
}

Lifan $\mathbf{Y}^{1}$, Maria $\mathbf{G}^{2}$, Mary $\mathrm{CK}^{1}$, Jacqueline $\mathbf{S}^{3}$, Mengjiao $\mathbf{S}^{1}$, Mark $\mathrm{T}^{4}$, Brooke $\mathbf{W}^{1}$ and Robert $\mathrm{E}^{1^{*}}$

${ }^{1}$ Department of Educational Psychology, University of Wisconsin-Madison, USA

${ }^{2}$ Columbia Correctional Institution in Portage, Wisconsin, USA

3 International Forgiveness Institute, Inc., Madison, Wisconsin, USA

${ }^{4}$ Columbia Correctional Institution in Portage, Wisconsin, USA

*Corresponding author: Robert Enright, Department of Educational Psychology, University of Wisconsin-Madison, USA, Tel: +16084387230; E-mail: rd.enright@yahoo.com

Received date: March 20, 2017; Accepted date: April 11, 2018; Published date: April 16, 2018

Copyright: @ 2018 Lifan Y, et al. This is an open-access article distributed under the terms of the Creative Commons Attribution License, which permits unrestricted use, distribution, and reproduction in any medium, provided the original author and source are credited.

\begin{abstract}
Two case studies of men in maximum security prison are presented. The goal is to show that each of them has experienced a considerable injustice against them prior to their crime and imprisonment. Further, our intent is to show that as a result of the injustices against them, they now are experiencing severe psychological compromise. The link among unjust treatment, the development of resentment, and the related psychological compromise may be an impediment to cooperation with current attempts at rehabilitation. Perhaps it is time for corrections personnel to focus more on uncovering the stories of injustice so that the resultant resentment may be healed through Forgiveness therapy, which may take away one central motivation for hurting others.
\end{abstract}

Keywords: Injustice; Crime; Imprisonment; Psychological compromise

\section{Introduction}

In this journal our research team recently proposed a new approach to corrections. It is based on the model of the psychology of forgiveness by researchers at the University of Wisconsin-Madison and colleagues around the world [1]. The model hypothesizes that being treated unjustly by others can lead to resentment. If the resentment is deep and long-lasting, then this can lead to psychological and behavioral compromise such as heightened anxiety and depression and low self-esteem and hope for the future [2]. Deep resentment, which can turn to hatred, then can be a major motivation to hurt other people and therefore to engage in crime. If we can find a way to reduce the resentment, then we have eliminated one central motivation for crime.

Studies show that imprisoned persons have experienced a relatively high degree of trauma during childhood or adolescence [3-9]. The majority of imprisoned people have experienced lifetime trauma exposure, and high rates of them met the lifetime or current criteria of serious mental illness, including major depressive disorder, PTSD, et al. $[10,11]$. Psychological problems are experienced by those in prison such as substance abuse disorder [12], affective disorders [13], functional psychosis [14], depression, anxiety, high rates of suicide, and self-harm [15-17]. Anger remains an important area of study given the rising concern within communities over violent crimes [18-20].

Traditional rehabilitation methods primarily focus on cognitive modification, behavioral reinforcement, academic training, and emotion management training [21,22], not on actual cures for anger and related psychological compromise. Maximum security prisons create special challenges because of the possible severity of past injustices, current severity of psychological symptoms, and therefore the challenge of effective treatment in ameliorating these symptoms, particularly unhealthy anger.

Forgiveness therapy has been demonstrated to statistically reduce or eliminate excessive anger [2]. Studies support the finding that forgiveness has a significant positive effect both on people's physical and mental health $[23,24]$. Forgiveness therapy has been tried with a wide variety of people deeply hurt by others such as: incest survivors, elderly abused in many ways, emotionally-abused women, cardiac patients, adult children of alcoholics, people in residential drug rehabilitation, and others [23-31]. The efficacy of Forgiveness therapy has been supported in numerous studies as an evidenced-based treatment for the negative outcomes of abuse [2]. Research models of Forgiveness therapy do not exist for any correctional facility.

Forgiveness is a moral virtue in which an unjustly wronged person strives to reduce resentment toward an offender and to offer goodness of some kind toward the person [32]. To forgive is not to excuse wrongdoing, to forget, to necessarily reconcile, or to abandon the quest for justice. As with any virtue, such as justice or patience, it takes time to learn to forgive. The process usually starts with anger or confusion or sadness and only after a period of time is a person usually ready to consider forgiveness as an option. The forgiveness virtue differs from justice in this: Forgiveness is considered to be a supererogatory virtue in that it is the person's personal choice whether or not to engage in it. In contrast, the justice virtue is required of people in societies at least for certain acts (one must not deliberately drive through a red stop light while driving a car, for example). Following the initial period of anger or confusion, a person chooses to forgive, realizing that the injustice still is considered wrong if forgiveness occurs. The next step in the process usually is to try to see the inherent worth in the offending person. This usually includes seeing that person's weaknesses and struggles, not to condone, but to better understand the other in their wounded-ness. Understanding the other's inherent worth also includes seeing the other's humanity (the victim and offender can feel pain, 
each needs nutrition to live, both will die some day). This can lead to even a little compassion toward the offender, which begins to take away some of the unhealthy anger in the victim. The forgiveness process continues by asking the forgiver to bear the pain of what happened so that the pain is not passed to others, including the wrongdoer or innocent others who could become the victims of the stored-up wrath. From here the forgiver, when becoming psychologically stronger through forgiving, decides to exercise the virtue more deeply by giving a gift of some kind to the perpetrator. For example, this can take the form of a kind word to the person or about the person to others. Near the end of Forgiveness therapy, the forgiver begins to find new meaning in what was suffered and to find a new purpose in life such as helping others now with their pain, as an example [2].

One area in which Forgiveness therapy is beginning to develop, but needs to develop more pervasively, is in prisons. It is our contention that many of the people in prison have suffered serious injustices against them prior to their crimes. These injustices can start a cycle of violence that will remain without deep rehabilitation until the injustice is recognized, faced, and the offender forgiven. When people live with injustices that are unacknowledged and therefore unhealed in a psychological sense, then no amount of behavioral intervention will be effective until a way is found to reduce or even eliminate the resentment caused by the unjust prior treatment.

To begin laying the foundation for this new theory of forgiveness within corrections, we at the University of Wisconsin-Madison have begun a research program in which we have asked men in a maximum security prison to tell their story (if they have one) of any unjust treatment by others prior to their crime and imprisonment. To date, we have collected information on about 100 men. The data analysis is progressing. It is our intent here to present two case studies as a way to begin showing what we think is more pervasive than has been acknowledged in corrections, that some of those imprisoned are silently harboring grave injustices against them from times past. The effects of those injustices not only are not healed, but are deeply affecting the victims. What is encouraging to us is this: We now have a scientifically-supported way of healing this resentment which we think will have a bearing not only on the personal psychological health of the forgiver but also on a safer climate within prisons for other inmates, officers, and other workers and within the larger community if and when the person is released from prison. If deeply angry people hurt other people, then we are eliminating this one avenue of continued hurting of others.

From the recently completed study of about 100 participants, we now present the two case studies of men who are in maximum security prison. We present their stories of injustice as written down in one session. At the same time, each was given a series of psychological instruments and we describe the results of those. If the men, as we hypothesize, have serious injustices against them and if they are psychologically compromised because of this, then we are beginning to develop our rationale for Forgiveness therapy toward emotional and relational healing.

\section{Methods}

\section{Participants}

Person A is in his late 20's and has been in maximum security prison for over three years because of kidnapping, sexual assault, and strangulation. Person B is in his late 30's and has been in maximum security for over 15 years because of federal drug conspiracy charges and more than one murder.

\section{Instruments}

\section{Personal and criminal history}

This is a 9-item questionnaire helping us to get general knowledge of inmates' demographic information (age, ethnicity/race, education level, most recent job, where they lived prior the time in prison) and crime history (the first crime they committed, the crime that ultimately landed them in prison, how long they have been in maximum security prison)

\section{0-Item Enright forgiveness inventory (EFI-30)}

As a measurement of forgiveness, the EFI-30 is the short version of Enright Forgiveness Inventory (EFI) [33]. It includes three subscales: Affect behaviour and cognition with 10 items in each subscale. The introductory material at the beginning asks participants to focus on the worst injustice they experienced before their first imprisonment, and to indicate the person who unfairly treated them, time to event, degree of hurt and a brief description of the experience. Then participants were asked to think about the person who hurt them and rate the 30 items on a 6-point Likert scale ranging from "strongly disagree" to "strongly agree." Half of the items are negative statements, and reverse coding is done in the data analysis. An example of the positive items is "I feel warm toward him/her," and a negative one is "Regarding this person, I disapprove of him/her." If a person shows more forgiveness, he or she will score higher on the positive items and lower on the negative ones. Thus, the total forgiveness scores range from 30 to 180, with each subscale scores in the range of 10 to 60 . A higher score means more forgiving. Next, 5 pseudo-forgiveness questions were presented after the EFI-30, which asked participants to evaluate if the incident is really a hurtful event for them. One example is "I was never bothered by what happened." Participants responded on a 6-point scale ranging from "strongly disagree" to "strongly agree." The total pseudo-forgiveness scores range from 6 to 30. Those who had pseudo-forgiveness scores higher than 20 would have their responses eliminated from data analysis because they did not seem to have a real unfair situation or experience hurt. Finally, participants answered the question "To what extent have you forgiven the person you rated on this Attitude Scale?" by rating from 1 (not at all) to 5 (complete forgiveness). The one-item forgiveness is used to validate EFI-30 in data analysis.

\section{Anger scale, depression scale, and anxiety scale from the Patient-Reported Outcome Measurement Information System (PROMIS)}

Items on these scales focus on the participants' psychological status in the past seven days. Participants respond to each item on a 5-point scale from "Never" to "Always." Short forms generated from the item banks for anger, depression, and anxiety were used in this study. These assessments include 5 items in the anger scale, 8 items in the depression scale, and 7 items in the anxiety scale. Items are statements about the frequency of feeling angry, depressed, or anxious in the past 7 days. For example, one item in the anger scale is "In the past 7 days, I felt like I was ready to explode." All sentence structures of items in three scales are "In the past 7 days, I..." The total scores for the anger scale range from 5 to 25 , for the depression scale from 8 to 40 , and for 
the anxiety scale from 7 to 35 . The higher scores a participant rated in one scale, the angrier/more depressed/more anxious he/she was, in contrast with those who score lower. These scales have been validated [34-36]. The anger, depression, and anxiety short forms all have a correlation at 0.96 with their bank [34]. The full anger bank's reliability is above 0.93 across the majority of the score distribution. The correlation between anger bank and the Aggression Questionnaire is 0.51 . The reliability of the full anxiety bank was above 0.89 for most of the score distribution [34]. The anxiety bank is also correlated with other anxiety measurements: The Mood and Anxiety Symptom Questionnaire $(\mathrm{r}=0.80)$ and the Center for Epidemiological StudiesDepression Scale $(r=0.75)$. The reliability of the depression bank is above 0.92 for the majority of the score distribution [34,35]. It is also correlated with the Center for Epidemiological Studies-Depression Scale $(\mathrm{r}=0.83)$ and the Mood and Anxiety Symptom Questionnaire $(\mathrm{r}=0.72)$.

\section{The Herth Hope Index (HHI)}

The Herth Hope Index has 12 items and assesses optimism toward the future with questions such as: "I have a positive outlook on life;" "I am able to give and receive caring/or love;" and "I believe that each day has potential." These questions assess connectedness to positive expectations for the future, inter-connectedness with other people, and inner positive expectancy. Participants responded on a 4-point scale ranging from "strongly disagree" to "strongly agree." Two items need to be reversely coded, and the total hopes score ranges from 12 to 48 . A higher score means more hopefulness toward the future. HHI is the abbreviate version adapted from the Herth Hope Scale (HHS). Its alpha-coefficient was 0.97 with a 2-week test-retest reliability of 0.91 . Criterion-related validity was established by correlating the HHI with the parent HHS $(r=0.92)$, the Existential Well-Being Scale $(r=0.84)$ and the Nowotny Hope Scale $(r=0.81)$. Divergent validity with the Hopelessness Scale was established $(r=-0.73)[36,37]$.

\section{Marlowe-crowne social desirability scale (20-item short version)}

This scale was used here to measure if a participant is "faking good" to meet the social desirability in psychological tests. It also assesses the degree to which each participant is taking this set of questionnaires seriously or not. This 20 -item short version of the Marlowe-Crowne Social Desirability Scale $[37,38]$ with 20 statements using a true/false response format. An example of a question is "I never hesitate to go out of my way to help someone in trouble." A participant gets 1 point for each "True" response and 0 point for each "False" response to 10 socially desired statements, and the reverse points to 10 not socially desired statements. Scores range from 0 to 20. A higher score represents a higher tendency of "faking good" in the test. This scale has been used in many psychological studies and has a reliability of 0.88 . It is correlated with the Edwards social desirability scale ( $\mathrm{r}=0.35)$. It also significantly correlates with many MMPI variables: Defensiveness $(\mathrm{K})$ $(\mathrm{r}=0.40)$, Lie (L) $(\mathrm{r}=0.54)$, Infrequency $(\mathrm{F})(\mathrm{r}=-0.36)$, Psychopathic Deviate $(\mathrm{Pd})(\mathrm{r}=-0.41)$, and Schizophrenia $(\mathrm{Sc})(\mathrm{r}=-0.40)$.

\section{Procedures}

After signing the consent forms, participants were asked to finish the following 7 scales: Personal and criminal history, anger scale, depression scale, anxiety scale, EFI-30, the Herth hope index and social desirability scale. All scales were presented in randomized order. Even though the anger, depression, and anxiety scales are all part of the developed PROMIS package of NIH, they were separated for this assessment and thus could occur in any order for any participant. The procedures of recruitment, survey administration, and data collection were followed as outlined in the approved protocol for the department of corrections and the university of Wisconsin-Madison's institutional review board.

\section{Results}

\section{Person A}

We deliberately have altered some of the details so that the neither identities of neither Person A nor Person B can be identified. Person A, when he was in early childhood, began to be sexually assaulted by a foster-teenager who was living with him and his aunt. For three years and "Just about every night," the foster teenager, who shared the same bedroom as Person A inappropriately touched him, penetrated him, and engaged in oral sex despite the protestations of the participant. $\mathrm{He}$ was repulsed by the actions, but his aunt did not believe him even though Person A was convinced that she knew what was happening. He reports a time, when these sexual assaults were just beginning, that his aunt walked near the room. The assailant quickly put the participant down and pretended to be asleep in his own bed. In other words, there was a failure of his caretaker to protect the participant at a very young age. Finally, because of a crime committed by the fosterteenager, he was removed from the home.

Person A's report is that he felt deeply ashamed. He became angry and this anger has stayed with him to this day. He reports sometimes blacking out in a rage. He reports that no one was there to help him and so his trust is deeply damaged. Even though he tried to alert family members, he says it "went on dead ears." From a laughing happy child, he reports becoming increasingly "silent" and becoming a loner. Although he tried to talk with others, it never happened and so he has kept this secret deep within him his entire life.

He now says that the silence he experiences within himself and the silence from family have contributed to his deep sense of injustice and anger. What happened to him contributes now to an inner psychological hurt that is contributing to his choice to harm others. It is worth noting that one of his crimes is sexual assault, what happened to him in early childhood.

Our first task was to ascertain whether or not the participant was telling the truth and we screen this both by the social desirability scale score and the score on the 5-item pseudo-forgiveness subscale. His score on social desirability is a low 5 , showing that he tells the truth about himself. His score on pseudo-forgiveness was the lowest possible score of 5 showing that he does see a serious problem with the fosterteenager's behavior and so he is not excusing that behavior.

His score on the Enright forgiveness inventory-30 is a 35, with the lowest possible score being 30 . This shows a strong lack of forgiveness, which was replicated with the one-item question about forgiveness, on which he scored a 1, "not at all" forgiving. His scores on each of the mental health variables of current anger, anxiety, and depression all were in the severe range, showing deeply compromised psychological health. His hope for the future was below both the mean and the median for the Herth Hope Index. 


\section{Person B}

Person $B$, when he was in his early teenage years, began to date a popular girl who was friendly with a rival gang. When he broke up with her, she told the leader of the other gang that Person B molested her. The result was that gang members went to his home and "beat me up in front of my Mom." As he got older, fights continued, including "shoot outs" with members of the rival gang. This included murders, of which he was charged with more than one. The violence went on for over 5 years.

Person B's report is that he first felt scared and then, over the years, this turned to hatred and a quest for revenge. He reports being tired of being bullied. As with Person A, he was from a broken home (his words) and so no one was there to help him. As happened with Person A, this participant says that he never has received help in dealing with his past history of unjust treatment toward him. There is a silence that he maintains about the violence that is taking a toll on him.

He now says that the teenage experience of frequent violence against him has contributed to his crimes and to his poor mental health, which he says includes the continual challenge of insomnia and unhealthy anger issues. What happened to him, as he himself reports, contributes now to his choice to harm others. Because he became stressed, depressed, and suicidal, he "Just stopped caring about anything." It is worth noting, as in the case of Person A, some of his crimes include physical violence against others, what happened to him in his early teenage years.

His Social Desirability Scale score is 10 (highest score is 20), not showing a high degree of "faking" his responses. His score on pseudoforgiveness was the lowest possible score of 5 showing that he does see a serious problem with the physical attacks on him and so he is not excusing that behavior.

His score on the Enright Forgiveness Inventory-30 is a 57 (again, the lowest possible score is 30 and the highest is 180). This shows a definite lack of forgiveness, which was replicated with the one-item question about forgiveness, on which he scored a 1, "not at all" forgiving. His scores on each of the mental health variables of current anger, anxiety, and depression all were in the severe range, showing deeply compromised psychological health. His hope for the future was below both the mean and the median for the Herth Hope Index.

\section{Discussions}

Two men from different backgrounds share severe injustices against them when they were young. Both remained silent about their challenged lives until this study when they were asked to share their life histories. Both currently are experiencing, from their own selfreports, the psychological and behavioral effects of their experienced injustices. It is important to note that in each case the crimes against them are continued in their crimes against others.

A major finding from these two case studies is that each reports that what happened to them is having a direct effect on the quality of their psychological and behavioral health even now. The results from this investigation are that their anger, anxiety, and depression are severe in each participant's case. This should not be seen as unusual. The extent to which this is typical awaits further investigation.

What we have now are two profiles that are a cause for hope. We say that because Forgiveness therapy has been shown on many occasions to reduce and even eliminate deeply held resentments which, in turn, can reduce and even eliminate psychological depression [24,30,39].

Perhaps it is time to test the effects of Forgiveness therapy on those in prison who show profiles similar to Persons A and B here. When we are presented with: a) severe injustices against a person; b) deep resentment as seen in low forgiveness scores; c) an acknowledgement by the participants that past injustices are contributing to current crime and psychological compromise; and d) the psychological compromise is severe, then these individuals are good candidates for forgiveness therapy [40,41]. What is important to note is that current corrections approaches do not yet include this kind of thinking. It seems to us that shifts in counseling programs that do not supplant current approaches but instead supplement them with Forgiveness therapy may prove to be more effective rehabilitation strategies. If the unhealthy anger is eliminated, if the people begin to be heard with regard to what happened to them, then perhaps they will have more energy, focus, and cooperation for rehabilitation strategies.

For the future, we recommend more studies in maximum, medium, minimum security prisons and juvenile detention center to ascertain how many people and to what extent these people show injustices against them prior to their crimes, the extent of un-forgiveness, and the presence of severe psychological compromise. If these studies support the hypothesis put forward here, then we have a rationale for opening up rehabilitation to forgiveness therapy. All in corrections, those imprisoned and those who serve them, as well as the larger community, may be the beneficiaries.

\section{References}

1. Enright RD, Erzar T, Gambaro M, Komoski MC, O’Boyle J, et al. (2016) Proposing forgiveness therapy for those in prison: An intervention strategy for reducing anger and promoting psychological health. J Foren Psy 1:116.

2. Enright RD, Fitzgibbons RP (2015) Forgiveness therapy: An empirical guide for resolving anger and restoring hope. Washington, American Psychological Association, USA.

3. Collins JJ, Bailey SL (1990) Traumatic stress disorder and violent behavior. J Trauma Stress 3: 203-220.

4. Dargis M, Newman J, Koenigs M (2016) Clarifying the link between childhood abuse history and psychopathic traits in adult criminal offenders. Personal Disord 7: 221-228.

5. Dembo R, Williams L, La Voie L, Berry E, Getreau A, et al. (1990). Physical abuse, sexual victimization and marijuana/hashish and cocaine use over time: A structural analysis among a cohort of high risk youth. J Prison Jail Health 9: 13-43.

6. Dohrenwend BP (2000) The role of adversity and stress in psychopathology: Some evidence and its implications for theory and research. J Health Soc Behav 41: 1-19.

7. Guthrie RK (1999) The prevalence of posttraumatic stress disorder among federal prison inmates. Unpublished doctoral dissertation, West Virginia University, Morgantown, USA.

8. Logan TK, Walker R, Staton M, Leukefeld C (2001) Substance use and intimate violence among incarcerated males. JOFV 16: 93-114.

9. Weeks R, Widom CS (1998) Self-reports of early childhood victimization among incarcerated adult male felons. J Interpers Violence 13: 346-361.

10. Green BL, Miranda J, Daroowalla A, Siddique J (2005) Trauma exposure, mental health functioning, and program needs of women in jail. CAD 51: 133-151.

11. Lynch SM, DeHart DD, Belknap JE, Green BL, Dass-Brailsford P, et al. (2014) A multisite study of the prevalence of serious mental illness, PTSD, and substance use disorders of women in jail. Psychiatr Serv 65: 670-674. 
Citation: Lifan Y, Maria G, Mary CK, Jacqueline S, Mengjiao S, et al. (2018) The Silent Injustices against Men in Maximum Security Prison and the Need for Forgiveness Therapy: Two Case Studies. J Foren Psy 3: 137. doi:10.4172/2475-319X.1000137

Page 5 of 5

12. Fazel S, Bains P, Doll H (2006) Substance abuse and dependence in prisoners: a systematic review. Addiction 101: 181-191.

13. Davison S, Leese M, Taylor PJ (2001) Examination of the screening properties of the Personality Diagnostic Questionnaire 4+ (PDQ-4+) in a prison population. J Pers Disord 15: 180-194.

14. Smith C, O'Neill H, Tobin J, Walshe D (1996) Mental disorders detected in an Irish prison sample. Crim Behav Ment Health 6: 177-183.

15. Zamble E, Porporino F (1988) Coping behavior and adaptation in prison inmates. Springer-Verlag, New York, USA.

16. Cooper C, Berwick S (2001) Factors affecting psychological well-being of three groups of suicide-prone prisoners. Curr Psychol 20: 169-182.

17. Cooper C, Livingston M (1991) Depression and coping mechanisms in prisoners. Work \& Stress 5: 149-154.

18. Novaco RW (1994) Anger as a risk factor for violence among the mentally disordered. VMDRA 21-59.

19. Howells K (1989) Anger management methods in relation to the prevention of violent behavior. HANA 153-181.

20. Howells K, Hollin CR (1989) Clinical approaches to violence. Chichester: John Wiley \& Sons, USA.

21. Holbrook MI (1997) Anger management training in prison inmates. Psychol Rep 81: 623-626.

22. Kandel HJ, Ayllon T, Roberts MD (1976) Rapid educational rehabilitation for prison inmates. Beha res ther 14: 323-331.

23. Waltman MA, Russell DC, Coyle CT, Enright RD, Holter AC, et al. (2009). The effects of a forgiveness intervention on patients with coronary artery disease. Psychol Health 24: 11-27.

24. Lee YR, Enright RD (2014) A forgiveness intervention for women with fibromyalgia who were abused in childhood: A pilot study. Spiritual Clin Pract 1: 203-217.

25. Al-Mabuk R, Enright RD, Cardis P (1995) Forgiveness education with parentally love deprived college students. J Mor Edu 24: 427-444.

26. Gambaro ME, Enright RD, Baskin TA, Klatt J (2008) Can school-based forgiveness counseling improve conduct and academic achievement in academically at-risk adolescents?. J Res Edu 18: 16-27.

27. Hansen MJ, Enright RD, Baskin TW, Klatt J (2009) A palliative care intervention in forgiveness therapy for elderly terminally-ill cancer patients. J Palliat Care 25: 51-60.

28. Hebl JH, Enright RD (1993) Forgiveness as a psychotherapeutic goal with elderly females. Psychotherapy 30: 658-667.
29. Lin WF, Mack D, Enright RD, Krahn D, Baskin T (2004) Effects of forgiveness therapy on anger, mood, and vulnerability to substance use among inpatient substance dependent clients. J Consult Clin Psychol 72: 1114-1121.

30. Reed GL, Enright RD (2006) The effects of forgiveness therapy on depression, anxiety, and post-traumatic stress for women after spousal emotional abuse. J Consult Clin Psychol 74: 920-929.

31. Rye MS, Pargament KI (2002) Forgiveness and romantic relationships in college: Can it heal the wounded heart?. J Clin Psychol 54: 419-441.

32. Enright $\mathrm{RD}$ (2012) The forgiving life: A pathway to overcoming resentment and creating a legacy of love. American Psychological Association, USA.

33. Subkoviak MJ, Enright RD, Wu CR, Gassin EA, Freedman S, et al (1995) Measuring interpersonal forgiveness in late adolescence and middle adulthood. J Adol 18: 641.

34. Cella D, Riley W, Stone A, Rothrock N, Reeve B, et al. (2010) The PatientReported Outcomes Measurement Information System (PROMIS) developed and tested its first wave of adult self-reported health outcome item banks: 2005-2008. J Clin Epidemiol 63: 1179-1194.

35. Pilkonis PA, Yu L, Dodds NE, Johnston KL, Maihoefer CC, et al. (2014) Validation of the depression item bank from the Patient-Reported Outcomes Measurement Information System (PROMIS ${ }^{\circledR}$ ) in a threemonth observational study. J Psychiatr Res 56: 112-119.

36. Rothrock NE, Hays RD, Spritzer K, Yount SE, Riley W, et al. (2010) Relative to the general US population, chronic diseases are associated with poorer health-related quality of life as measured by the PatientReported Outcomes Measurement Information System (PROMIS). J Clin Epidemiol 63: 1195-1204.

37. Herth K (1992) Abbreviated instrument to measure hope: Development and psychometric evaluation. JAN 17: 1251-1259.

38. Crowne DP, Marlowe D (1960) A new scale of social desirability independent of psychopathology. J Consult psychol 24: 349-354.

39. Strahan R, Gerbasi KC (1972) Short, homogeneous versions of the Marlow-crowne social desirability scale. J Clin Psychol 28: 191193.

40. Freedman SR, Enright RD (1996) Forgiveness as an intervention goal with incest survivors. J Consult Clin Psychol 64: 983-992.

41. Jordan BK, Schlenger WE, Fairbank JA, Caddell JM (1996) Prevalence of psychiatric disorders among incarcerated women: II. Convicted felons entering prison. Arch Gen Psychiatry 53: 513-519. 